\title{
Rapid mine development using efficient in-cycle shotcrete
}

\author{
F Erismann Sika Services AG, Switzerland \\ B Lindlar Sika Services AG, Switzerland \\ C Munoz Sika Chile, Chile \\ M Hansson Sika Services AG, Sweden \\ R Erlangga Sika Indonesia, Indonesia
}

\begin{abstract}
Fibre-reinforced shotcrete has proven to be the material of choice when it comes to rapid and efficient underground support in large mining projects. For large block caving projects, in-cycle shotcrete is particularly interesting as it allows rapid footprint development, thus shortening the construction time to access first ore from drawpoints. Application speed, applicability, yielding characteristics, durability and strength are the main favourable characteristics that make fibre-reinforced, sprayed concrete the go-to primary support component in most block and sublevel cave operations around the globe. However, integrating an effective shotcrete setup in mining operations requires good know-how in concrete production, spray application and the selection of the best performing materials.

Lessons learned from projects such as El Teniente, Grasberg, Kiruna, Chuquicamata and others are part of this paper. Particular focus is given on the screening of the right mix design for a given mining operation. Finding an optimised solution in terms of the accelerator and admixture selection, the choice of the right fibre and dosage as well as optimising the mix design from a cost performance perspective are key to harvesting the main benefits of an integrated shotcrete support. By doing so, the shotcrete will yield its main benefits such as high early strength development that allows fast re-entry time after spraying and high energy absorption capabilities of the cured shotcrete liner to cope with the expected lithostatic and mining-induced loads and deformations. A tool that has been proven successful is the Sika MiniShot device. It is a scaled down laboratory tool to efficiently screen for the right and best performing shotcrete mix in a fast and lean way.
\end{abstract}

Keywords: shotcrete, mining, accelerator, admixture, Sika

\section{Introduction}

Fibre-reinforced, sprayed concrete has contributed largely to efficient and rapid mine development of large-scale block and sublevel cave projects around the globe, particularly during the last two decades. This primary support method has proven successful in the global mining industry due to its fast and lean application, uniformity of the support, the yielding capabilities it provides and the quality control procedures that are reliable and relatively straight forward to follow.

Production and transportation of concrete for shotcrete applications can be scaled relatively easy with a view towards the planned consumption of a given development stage of the project. This is particularly important as shotcrete volumes will vary significantly once block cave developments shift from the access and support infrastructure to the actual footprint where haulage levels, as well as the undercut and extraction levels, need to be developed rapidly. However, providing the planned concrete output and shotcrete application quality is not without challenges. 
As illustrated in Figure 1, many of today's block cave developments require shotcrete volumes in excess of $80,000 \mathrm{~m}^{3}$ per annum; a volume that requires thorough quality control procedures to be in place during production, transportation and spray application. These procedures must be followed carefully, utilising the full range of value-adding chemicals and additives the industry offers today. Some of these value-adding systems briefly described in this paper range from the evaluation phase of the shotcrete to the day-to-day quality control protocols in terms of the required open time for transportation and the required shotcrete setting time for rapid in-cycle shotcrete applications that enable fast drifting and development schedules.

Tons of ore underground

mine capacity per day

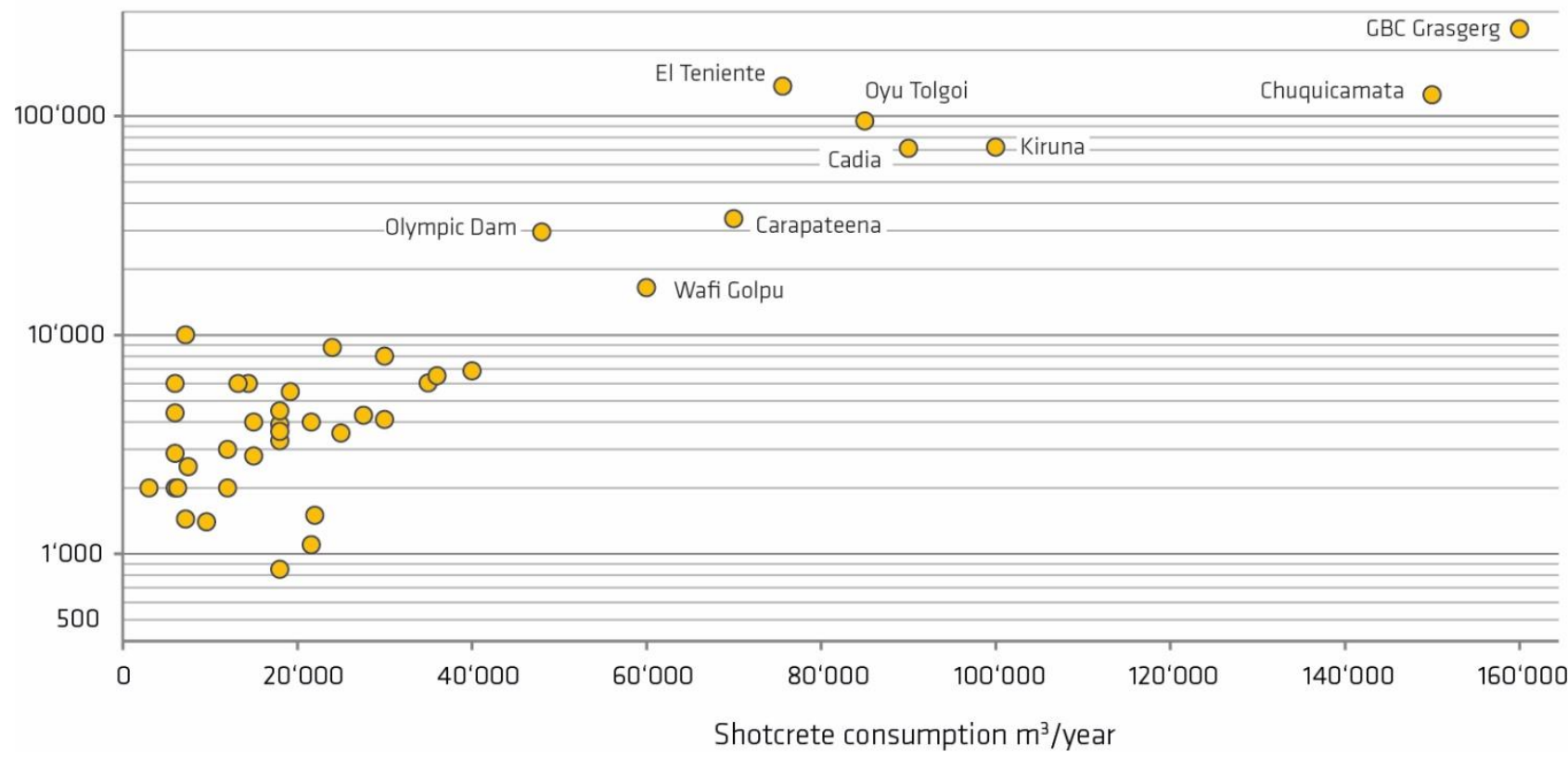

Figure 1 Annual shotcrete consumption as a result of the daily ore throughput of underground mining operations throughout the globe. Names indicate the current block or sublevel caves that are in operation, construction or planning phase

\section{Requirements}

The requirements of concrete and shotcrete, as well as the application range, have been extended greatly over the past 20 years. Landmark development projects of increased size, depth and challenging locations have generally raised the demand for complex concrete applications. Among the most challenging were underground construction projects such as the construction of the world's longest and deepest rail tunnel, the Gotthard base tunnel in Switzerland, partly under more than 2,500 $\mathrm{m}$ of lithological cover, and mining projects such as Kiruna in Swedish Lapland, the Grasberg Block Cave development in Indonesia and the Chuquicamata block cave development in Chile. All these projects pose very specific requirements for shotcrete. The challenging geographic and climatic locations represent major logistical hurdles for the supply of materials. The technical requirements are usually demanding in terms of the open time for long haulage distances and high early strength as well as the energy absorption of the sprayed concrete.

Maximising the open time and shortening the early strength development has been the major focus for product development over the years. Contractors and miners want to be on the safe side during the transportation of the concrete but require a fast setting and hardening of the shotcrete in order to re-enter the secured perimeters for subsequent bolt installations.

One of the projects with the most stringent early strength requirements for maximised development efficiencies is Kiruna. The in-cycle shotcrete requires early strengths of $4 \mathrm{MPa}$ after four hours at a minimum binder consumption. Additionally, the mix design was designed to reduce rebound of the shotcrete to a minimum and interact optimally with the added fibre in order to cope with seismic events 
and increased rock strain levels on the deeper installed sublevels. This was achieved by a specially designed plasticiser and a shotcrete accelerator that is customised to the cement used and the ambient environmental conditions at the site.

High-quality concrete demands strongly reduced water to binder ratios. This in turn has a strong effect on the workability of the concrete as a whole, and the lack of water as a natural plasticiser needs to be compensated with modern, high-range water reducers. This is illustrated in Figure 2 where the workability and the water-cement ratio are put into context.

During the construction of the Gotthard base tunnel for example, the workability and quality limits were extended beyond what was previously known and led to the development of various products that are now well-established in the market. The tunnel construction at Gotthard required a concrete that can deal with the extremely long transport distances of up to nine hours, including an $800 \mathrm{~m}$ long vertical slick line along the Sedrun shaft access to the point of use, as well as an accelerated curing of the placed inner liner concrete to reach $2.5 \mathrm{MPa}$ after 12 hours, and $5 \mathrm{MPa}$ after 18 hours.

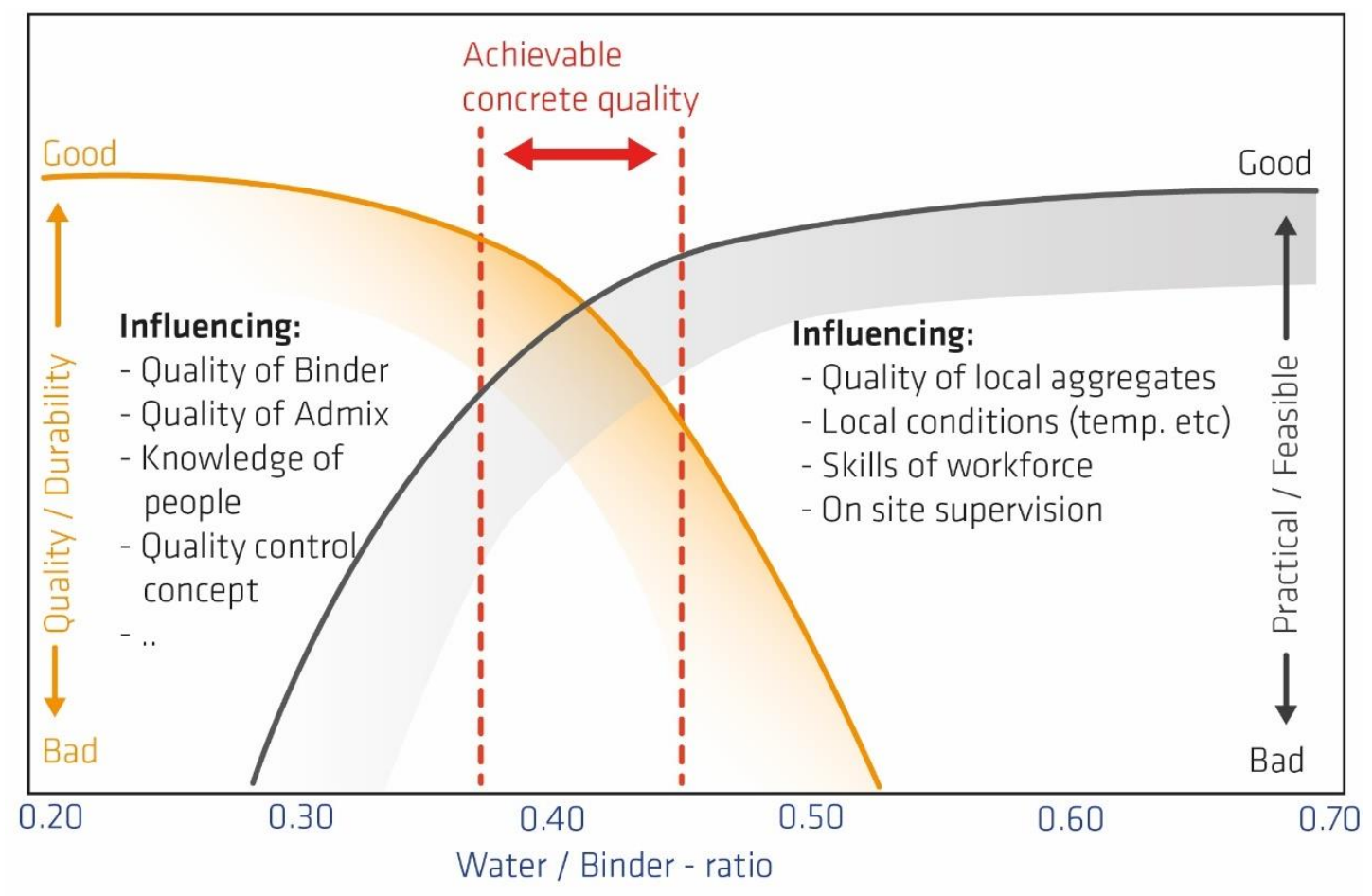

Figure 2 Schematic illustration of the workability and quality limits of concrete. A reduced water to binder ratio improves the strength of the concrete but has a detrimental effect on the workability (Schlumpf 2017)

\section{Problems and solutions}

Remote large-scale mining projects require customised solutions to deal with the required shotcrete volumes and quality. Table 1 outlines the problems and potential solutions to them.

For many large block cave projects, the location represents a major problem. Oyu Tolgoi, as well as Kiruna, need to deal with very harsh climatic conditions during the winter months, and Grasberg and Chuquicamata have very challenging and long supply routes. Choosing the right type of admixtures and reducing the amount of cement used for a certain strength requirement is critical to keep logistics and costs under control. 
Table 1 Problems and potential solutions related to concrete/shotcrete logistics, production and application often observed at large-scale mining projects

\begin{tabular}{|c|c|c|}
\hline Problem & Environment & Solution \\
\hline \multicolumn{3}{|l|}{ Workability } \\
\hline $\begin{array}{l}\text { Long haulage } \\
\text { distances }\end{array}$ & Long transportation routes & $\begin{array}{l}\text { Extended open time, hydration control admixtures, } \\
\text { retarders }\end{array}$ \\
\hline Line blockages & $\begin{array}{l}\text { Slick line transportation of } \\
\text { concrete }\end{array}$ & $\begin{array}{l}\text { Adjust mix design, increase slump, use } \\
\text { superplasticiser }\end{array}$ \\
\hline Poor access & $\begin{array}{l}\text { Shafts, narrow stopes, no } \\
\text { ramp }\end{array}$ & Dry or semi-dry shotcrete mixes, dry spray equipment \\
\hline \multicolumn{3}{|l|}{ Strength } \\
\hline $\begin{array}{l}\text { High early strength } \\
\text { requirements }\end{array}$ & Rapid mine development & Use of right admixtures, accelerators and mix designs \\
\hline $\begin{array}{l}\text { High energy } \\
\text { absorption }\end{array}$ & $\begin{array}{l}\text { Deep underground, } \\
\text { challenging geology }\end{array}$ & $\begin{array}{l}\text { Use of the right macrosynthetic fibre and dosage, } \\
\text { rapid early strength development }\end{array}$ \\
\hline $\begin{array}{l}\text { Acid attack of the } \\
\text { concrete }\end{array}$ & Acid mine drainage & $\begin{array}{l}\text { Use of matrix-densifying additives and macrosynthetic } \\
\text { fibres }\end{array}$ \\
\hline Abrasion & Orepasses, ore chutes & Use of abrasion resistant spray mortars/gunites \\
\hline Water & Excess water on substrate & Dry shotcrete mixes, drainage systems, injections \\
\hline \multicolumn{3}{|l|}{ Climate and logistics } \\
\hline Hot temperature & $\begin{array}{l}\text { Deep underground or } \\
\text { tropical location }\end{array}$ & Hydration control admixtures \\
\hline Cold temperature & Arctic location & Accelerator technology, concrete production \\
\hline Logistics & Remote location & $\begin{array}{l}\text { Onsite accelerator production and powder transport } \\
\text { and storage, use of macrosynthetic fibres }\end{array}$ \\
\hline Volume & Footprint development & $\begin{array}{l}\text { Not too many different mix design components, lean } \\
\text { mix, clever packaging, keep it simple }\end{array}$ \\
\hline \multicolumn{3}{|l|}{ Health and safety } \\
\hline $\begin{array}{l}\text { Environment, health } \\
\text { and safety }\end{array}$ & $\begin{array}{l}\text { Excess dust, use of } \\
\text { powders, alkaline materials }\end{array}$ & $\begin{array}{l}\text { Alkaline-free materials, liquefied silica fume, water } \\
\text { soluble, bagged materials, wet instead of dry spraying }\end{array}$ \\
\hline Bond to substrate & During spray application & Use right accelerator and mix design, clean substrate \\
\hline \multicolumn{3}{|l|}{ Costs } \\
\hline Overall costs & $\begin{array}{l}\text { Excess rebound and } \\
\text { cement consumption }\end{array}$ & $\begin{array}{l}\text { Adjust mix design, improve spray application, reduce } \\
\text { meshing, use of macrosynthetic fibres }\end{array}$ \\
\hline Excess waste & Short shelf life of chemicals & On-demand, onsite production of accelerator \\
\hline Maintenance costs & Wear of machinery & Adjust mix design, use pumping aids \\
\hline
\end{tabular}


Specially developed powder admixtures that can be dissolved in water on demand and at the point of use have proven to be very successful to avoid large heated/cooled storage and excessive waste, and to reduce trucking volumes. When large volumes are required, there is a need for a lean and easy mix design with a limited number of components. This allows large batch plant throughputs and avoids erroneous mixes that do not fulfil the quality control and hence need to be disposed. Such a system has recently been implemented at the Grasberg Block Cave batch plant; probably the largest underground batch plant on the globe.

The LKAB Kiruna site has been using a very lean and efficient mix design for many years in order to facilitate storage of large volumes and enable large concrete outputs at the batch plant. Additionally, customised mix designs are critical to deal with special concrete applications such as the transportation through slick lines. Also, ready-bagged dry or semi-dry mixes for dry or wet spraying can be very beneficial where transportation is limited (e.g. shaft access) or where mined perimeters are very narrow and the supply of wet shotcrete mixes is not feasible.

Mining in sulphide rich environments, which is usually the case when developing a mass mining setup in a mineralised porphyry, usually faces acid mine drainage within and around the installed infrastructure. Acid attack of the shotcrete and the reinforcement is the result. Densifying the matrix of the shotcrete by reducing the water-binder ratio and the use of special additives like silica fume in the mix or specially designed plasticisers will counter this problem in combination with high-performing macrosynthetic fibres that do not corrode. Such systems are implemented at both the Chuquicamata and the El Teniente sites in Chile.

Cost control is important when implementing large-scale shotcrete setups in mining operations. Reducing the rebound and cost optimising the mix design at a minimal cement consumption is crucial to achieve large cost savings and an efficient, in-cycle shotcrete operation. The optimised mix design, in combination with a well-trained nozzleman crew, will achieve the planned efficiency gains.

\section{$4 \quad$ Get the mix right - Sika MiniShot}

Testing shotcrete mixes is a costly, material-intensive and time-consuming undertaking. Large testing panels need to be sprayed and subsequently tested according to detailed guidelines such as the Norwegian Concrete Association Publication No. 7 (Norwegian Concrete Association 2001), the Austrian Shotcrete Guideline (Austrian Society for Construction Technology 2004) and laboratory standards such as EN 934-5 (European Committee for Standardization 2007).

For years, Sika was evaluating methods to simplify this procedure in order to screen the best-suited admixtures and accelerators in a laboratory-based, standardised environment. Sika MiniShot was developed in order to gain a competitive edge when it comes to the selection of the right shotcrete mix design for a certain project and to assist the mining customers with the cost performance optimisation of their current mixes. Today, Sika MiniShot is also acting as an important quality control tool for many mine sites across the globe. 
The idea is simple - scale down the shotcrete application to a lab-scale setup (Figure 3(a)) and observe cement hydration and strength development using ultrasonic waves by spraying the shotcrete on ultrasonic receivers. This receiver, or so-called 'pulsement' as shown in Figures $3(b)$ and (c), is then measuring the evolution of the acoustic properties of the sprayed material, and then links it with the mechanical strength by using a dedicated algorithm (Lootens et al. 2014). The results are astonishing and mimic what is actually happening in the field very accurately.

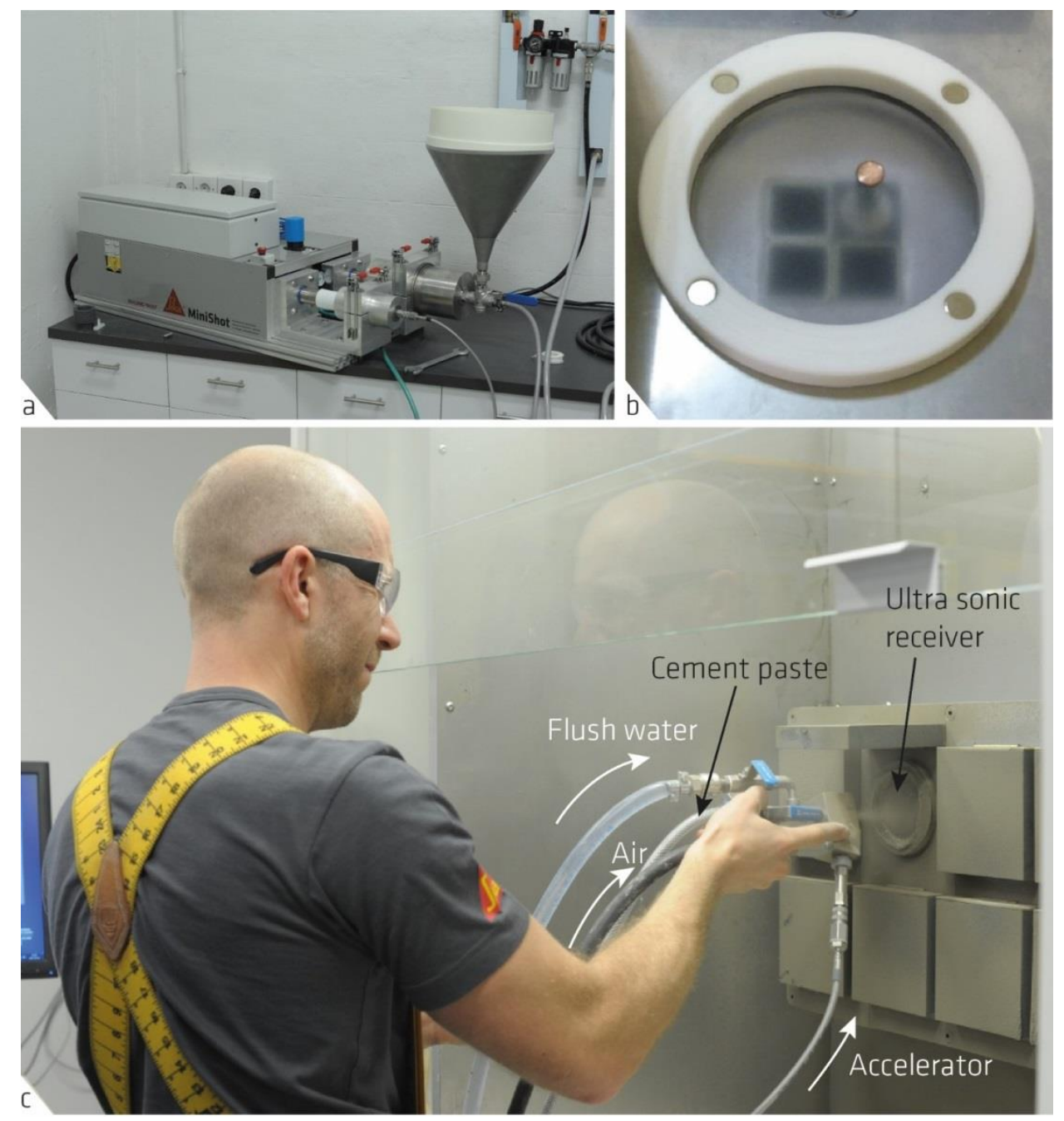

Figure 3 (a) MiniShot device including the pump for the cement paste and accelerator; (b) The ultrasonic receiver or 'pulsement'; and, (c) The MiniShot system operated in the lab by spraying the accelerated cement paste directly on the pulsement sensors

Figure 4(a) shows strength developments in MPa over time with real sprayed specimens using a large SPM 500 spray rig at the Hagerbach underground testing facility in Switzerland, using different accelerator types. Figure $4(\mathrm{~b})$ shows the results with the same mix design, without the aggregates but using the sieved fine fractions of the sand, but sprayed with Sika MiniShot, using the same accelerator types (after Lindlar et al. 2014). Furthermore, there is almost no data fluctuation visible in the shear strength curves (Figure 4(b)) compared with the high data variance when evaluating the results from the actual real-scale field trials. 


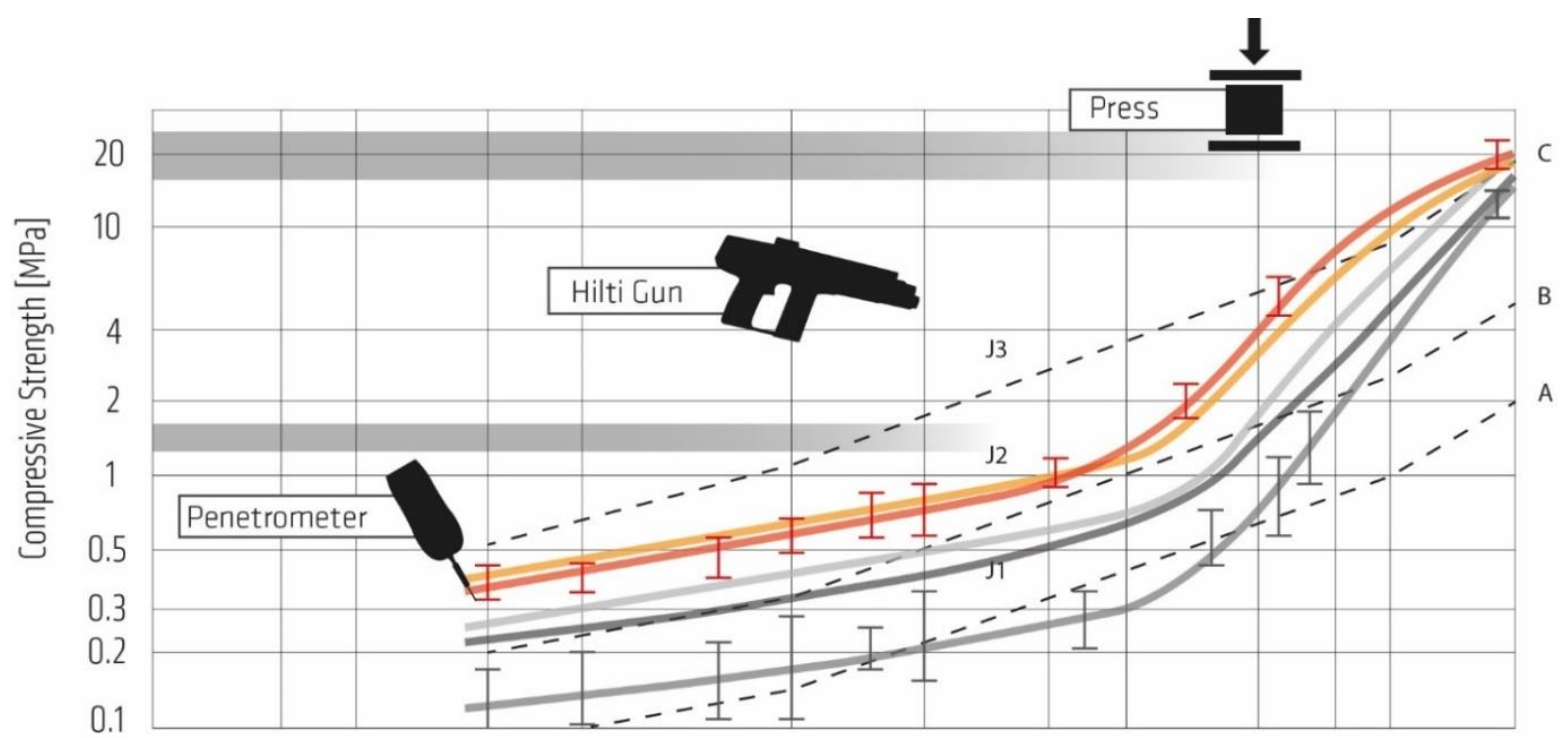

(a)

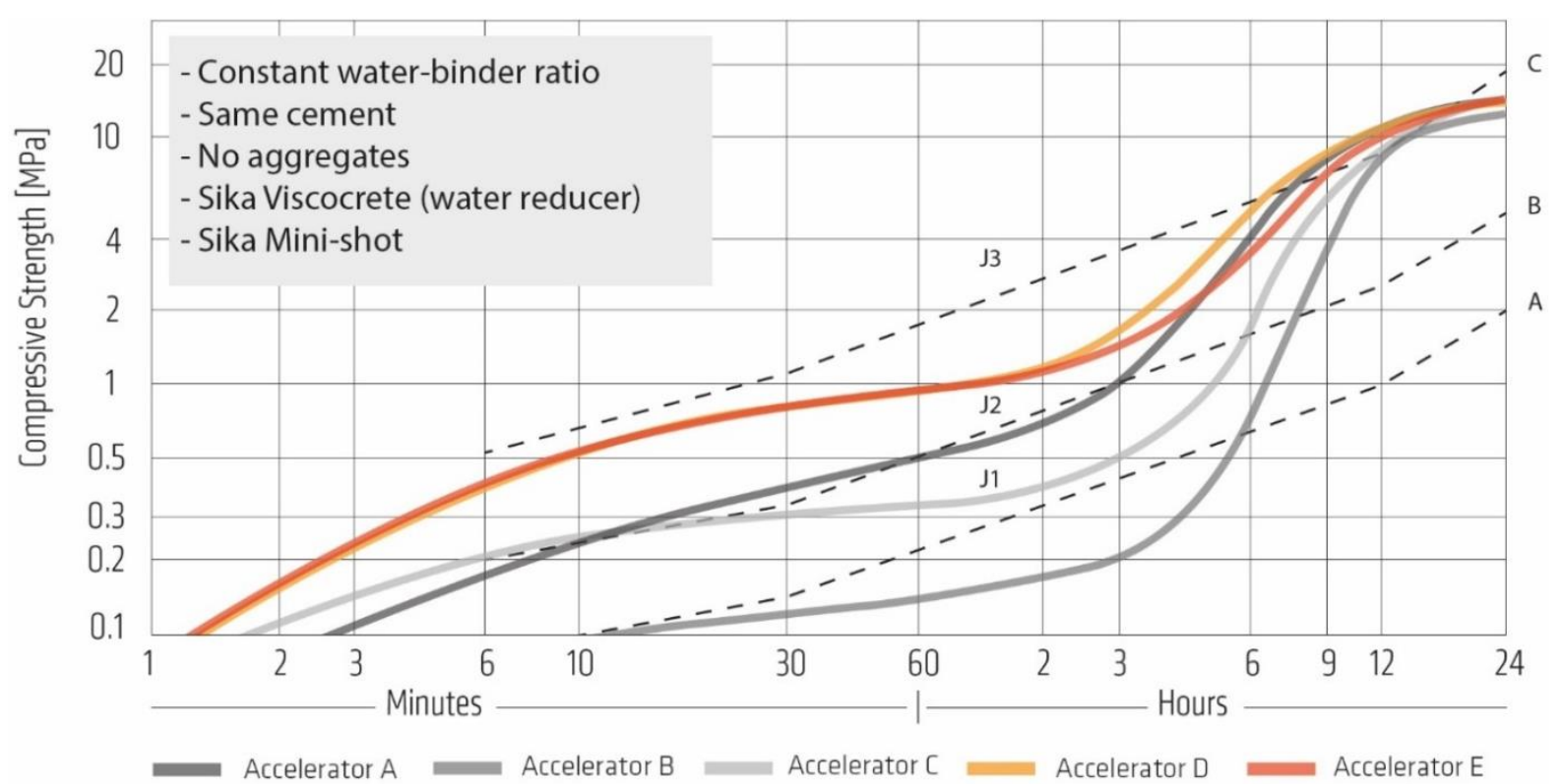

(b)

Figure 4 Comparison of shotcrete strength development from (a) large-scale site trials; and, (b) MiniShot trials using the same mix design for different accelerators

Another advantage is that the MiniShot device measures the starting point of the chemical reaction between the shotcrete accelerator and the cement and fine fraction of the shotcrete mix. It also allows continuous measurement of the strength development of the sprayed specimen immediately after spraying and over a period of three days, and not just periodic testing as used in large field trials. The obtained strengths can be well-correlated to the standardised penetration methods such as Vicat, Penetrometer, Hilti stud gun and compression or flexural strength tests (Lootens et al. 2014) as shown in Figure 4.

The main difference between the MiniShot tool and large onsite spraying of shotcrete is the lack of sand and aggregates when using the scaled-down MiniShot equipment. In shotcrete, sands and aggregates represent the largest solid particle fraction by volume, but at the concrete's early age are basically just inert, rigid filler material with no effect on the actual chemistry which is so important for the early-stage strength development of the material (Oblak et al. 2012). This is among the main reasons why MiniShot results correlate well with field results. 


\section{Conclusion}

Shotcrete has become the main component of the primary support installation in most modern large-scale mining projects globally, in particular block and sublevel caving projects. In combination with macrosynthetic fibres, shotcrete has proven to be a versatile material which is fast and safe to apply, covers large surface areas and can be controlled in terms of strength and yielding qualities. More importantly, shotcrete usage can be scaled depending on the development stage of a project and well-integrated into rapid, in-cycle, mine development schemes. However, shotcrete comes at a cost, and the production and application of shotcrete needs dedicated and well-trained personnel and a good selection of the right materials in order to cost optimise the shotcrete operation and to avoid excessive waste from rebound and excess material storage. By using special admixtures, some of them can be dissolved directly at the site without the need for excess storage and logistic costs. A lean and cost-effective shotcrete can be produced and applied, improving the overall efficiencies of the mining operation and providing a safe, durable and dynamic support for mining personnel. Sika MiniShot has proven to be a ground-breaking innovation for material screening for shotcrete and adds value when it comes to the selection of the right material and quality control of the sprayed concrete.

\section{References}

Austrian Society for Construction Technology 2004, Sprayed Concrete Guideline, Austrian Society for Construction Technology, Vienna.

European Committee for Standardization 2007, EN-934-5:2007, Admixtures for Concrete, Mortar and Grout - Part 5: Admixtures for Sprayed Concrete - Definitions, Conformity, Making and Labelling, European Committee for Standardization, Brussels.

Lindlar, B, Oblak, L, Lootens, D \& Stenger, C 2014, 'From tunnel to laboratory: Scaling of shotcrete testing', in T Beck, O Woldmo \& S Engen (eds), Proceedings of the Seventh International Symposium on Sprayed Concrete - Modern Use of Wet Mix Sprayed Concrete for Underground Support, Tekna - The Norwegian Society of Graduate Technical and Scientific Professionals, Oslo, pp. 282-286.

Lootens, D, Hansson, M, Oblak, L \& Lindlar, B 2014, 'Ultrasonic wave propagation for strength measurements: Application in shotcrete', in T Beck, O Woldmo \& S Engen (eds), Proceedings of the Seventh International Symposium on Sprayed Concrete - Modern Use of Wet Mix Sprayed Concrete for Underground Support, Tekna - The Norwegian Society of Graduate Technical and Scientific Professionals, Oslo, pp. 287-293.

Norwegian Concrete Association 2001, Sprayed Concrete for Rock Support, Publication No. 7, Norwegian Concrete Association, Oslo.

Oblak, L, Lindlar, B \& Lootens, D 2012, 'Continuous monitoring of strength evolution of shotcrete', in W Kusterle (ed.), Proceedings of the 10th Shotcrete Conference (Spritzbeton-Tagung 2012).

Schlumpf, J 2017, Sika at Work, Gotthard Base Tunnel - Project of the Century, Sika special publication, Sika Services AG, Zürich. 